\title{
Making Hemp Choices: Evidence from Vermont
}

\author{
Jane Kolodinsky ${ }^{1, * \mathbb{D}}$, Hannah Lacasse ${ }^{1}$ and Katherine Gallagher ${ }^{2}$ \\ 1 Department of Community Development and Applied Economics, University of Vermont, \\ Burlington, VT 05405, USA; hannah.lacasse@uvm.edu \\ 2 Mad River Valley Planning District, Waitsfield, VT 05673, USA; kati@mrvpd.org \\ * Correspondence: jane.kolodinsky@uvm.edu
}

Received: 10 March 2020; Accepted: 29 July 2020; Published: 4 August 2020

\begin{abstract}
Hemp's reemergence in the United States' economy presents an opportunity for a new category of sustainable product choice for consumers. This study fills a gap in knowledge about which consumers are currently aware of or choosing hemp products using the theory of choice alternatives and a statistically representative survey from a top ten hemp producing US state. Findings reveal high levels of consumer awareness and consideration of hemp products in general and a smaller evoked/choice set. Cannabidiol products appear most often in our sample's choice set; we examined these specifically. Other hemp products also appear, including clothing and textile, personal care, building material, and food products. Bivariate logistic regression results show that older respondents are more likely to be in the unaware set for hemp products in general and for cannabidiol products. Politically liberal respondents are more likely to be in the evoked/choice set for hemp products in general and for cannabidiol products. No demographic variables are significantly associated with being in the consideration set for hemp products in general. Younger and more educated respondents are more likely to consider cannabidiol products. As hemp represents a nascent but growing market, this study provides a baseline from which to build understanding of consumer choice alternatives.
\end{abstract}

Keywords: hemp; consumer demand; Vermont

\section{Introduction}

Natural and more environmentally friendly alternatives are being sought by consumers, resulting in transitions away from synthetic materials and pharmaceuticals, fossil fuels, and single-use items and towards natural fibers and medicines, energy efficiency, and durability [1-3]. Hemp has the potential to contribute to these sustainability goals as a sustainably grown crop and natural ingredient for consumer product alternatives such as textiles [4], biofuels [5,6], food and beverages [7], hemp concrete [8], paper [9], shampoos and skin care products [10], cannabidiol for non-psychotropic medical treatment [11-13], composites [14], and animal bedding [15]. Hemp's agronomic benefits may contribute to farmer and planetary sustainability, thereby appealing to consumers in search of products that promote sustainability.

Hemp is cited as one of the top five most biodiversity friendly crops, outperforming major monocrops like cotton, wheat, and maize [16,17]. Its inclusion in crop rotation cycles is noted as a potential complement to food production rather than a competitor [5]. Hemp can contribute to greenhouse gas reduction strategies as a low-energy crop [18]. It also has a number of characteristics that are well-suited for sustainability at the farm level. Hemp has high establishment rates, serving as a lower investment option that provides quicker returns to farmers [5]. It can act as a rotation crop, adding biological and financial diversity for existing farmers [19-21]. Both the seed and stem fiber of the plant can be processed, providing opportunity for double harvest [17]. Hemp is also cited for agronomic sustainability, including a root structure that is beneficial for soil improvement and can hold 
up to nitrogen poor soils [5,22]. It is rot resistant and fast growing [21-23]. The crop is competitive with weeds and rarely experiences devastating insect damage or disease outbreaks [19]. As a result, hemp has relatively low input requirements for pesticides and herbicides [18,24]. However, there is potential for greater input requirements should hemp production be pursued more intensively $[13,16]$. Despite these limitations, hemp continues to be cited for its potential as a sustainable crop and input into manufactured consumer products.

Hemp can be processed into a number of sustainable consumer products. Hemp fiber is highly durable, stronger than cotton, and resistant to water and saline damage $[17,21]$. As a paper product, hemp fiber has been found to have a longer life cycle and be more recyclable than paper made from wood pulp [14,18]. Hemp can act as an energy-efficient option for insulation [17]. Cannabidiol (CBD), a naturally occurring, non-psychoactive compound found in hemp plants, has also been demonstrated effective in therapeutic treatments [25].

Though hemp has many benefits, its historical regulatory ties to marijuana impeded its production and consumption since the 1950s [21,26]. Interest in hemp production resurfaced in the late 1990s and initiated regulatory changes across the state and federal levels, culminating with the passing of the 2018 Hemp Farming Act which federally legalized hemp's production $[27,28]$. Hemp has since captured the attention of producers and consumers alike. The United States Department of Agriculture (USDA) reports a substantial increase in hemp production in the US, rising from 0 acres in 2013 to 90,000 acres in 2018 [29]. The number of registered hemp producers in 2018 was more than thirteen times that of 2014 [29]. Market research estimated that 2017 hemp product sales were valued at $\$ 820$ million [30].

Amid hemp's reemergence as an agricultural commodity in the US, evidence-based data and research are critical to inform producers seeking to effectively plan for and participate in this renewed sector. A 2019 survey found that market demand was the most highly sought research category for hemp among producers [31]. However, there is an absence of information on consumer demand for hemp products at the individual level. The USDA cites this lack of reliable, peer-reviewed data as a barrier to nurturing this growing market [29]. Using data from a representative sample from Vermont, US, we contribute to this gap in knowledge by identifying consumer awareness/consideration and evoked/choice sets and related socio-demographic characteristics.

\subsection{Literature Review: Sustainable Consumption}

Given the absence of evidence-based, peer reviewed literature on consumer demand segments for hemp in the US, we reviewed literature that examined the association of socio-demographics with sustainable consumption, both generally and for specific product categories most closely related to hemp.

Research seeking to characterize sustainable consumption behavior using socio-demographic variables is vast but inconclusive. Some literature has found that socio-demographic variables are not significant determinants of sustainable consumption and, alone, fail contribute to the segmentation of green marketing [1,2,32]. Others find that socio-demographic variables, such as age, gender, and education, are linked to green consumption, albeit inconsistently $[3,33,34]$. This may be attributed to the increasingly complex decisions consumers face in order to engage in sustainable lifestyle choices [2]. Consumption behaviors related to more specific products have found that socio-demographics do play a role when characterizing consumer segments for therapeutic foods [35], sustainable apparel [36,37], sustainable wood products [38], sustainable convenience foods [39], food supplements [40], and alternative medicine [41]. Hemp has emerged as an ingredient in all of these products.

\subsection{Hemp in Vermont}

In the wake of the hemp revival across the US, Vermont was at the forefront of the crop's production and research. An early adopter of hemp legislation, Vermont authorized the cultivation and production of hemp in 2013 [42]. This positioned Vermont to be one of the first states to develop a hemp pilot program in response to the passing of the 2014 Farm Bill [43]. Researchers have since been exploring 
the agronomic feasibility of hemp as a cash crop [44-47]. Meanwhile, interest in hemp, both as a crop and product, have grown in Vermont as regulatory barriers to production have diminished [48-50]. A 2018 report by Hemp Industry Daily named Vermont one of the top ten hemp producing states in the US [51]. Opportunity for and interest in hemp production in Vermont have expanded even further with the passing of the 2018 Farm Bill [29,52,53]. From 2013 to 2019, the number of registered hemp growers has increased from nine to 300, with 4500 acres of land registered for production for the 2019 growing season [54]. Amid this swell in hemp interest, CBD products are the focus of producers and consumers alike [55-57]. The Vermont Agency of Agriculture stated that about $75 \%$ of registered hemp growers are growing for hemp's floral material or biomass, the part of the plant used for CBD production $[45,52]$. There is concern that this market will become quickly saturated, in terms of both demand and processing capacity, leaving some hemp producers behind [57,58]. However, evidence-based research on consumer demand for hemp-based products in Vermont is absent.

Faced with an increasingly favorable political landscape and a rising interest in hemp production among farmers and consumers, evidence-based research on hemp's feasibility in Vermont is critical to inform producers seeking to effectively plan for and participate in this renewed sector. Though Vermont has set itself up to be an early leader in hemp production, there is still a limited understanding of whether consumers know about, are considering purchasing or have actually purchased hemp products.

\subsection{Theory: Choice Alternatives}

There was no legal US-produced hemp marketplace between the passage of the Marihuana Tax Act of 1937 and the 2014 Farm Bill [43,59]. In addition, there is no empirical literature on consumer demand specifically for hemp. Our conceptual model, therefore, uses classic marketing theory, specifically Narayana and Markin's [60] alternative conceptualization of Howard and Sheth's [61] theory of consumer behavior. While Narayana and Markin's [60] put forth the idea of how new brands enter a consumer's awareness, evoked, inert, or inept choice set, we modify the conceptualization from a new brand to a new product category, namely, sustainable products with hemp ingredients (See Figure 1). Rarely does a truly new and novel product category enter the market to compete with current offerings. Before we can investigate why consumers are categorized into the various choice sets, how they arrived there, or whether marketers can nudge them from an undesirable (unaware, inert, inept) set into consideration, evoked and ultimately a hemp choice set, we must first understand who is in each category. Given the naissance of hemp in the United States, we utilized the concept of choice sets to identify the size of each set and their relationships to consumer demographic characteristics.

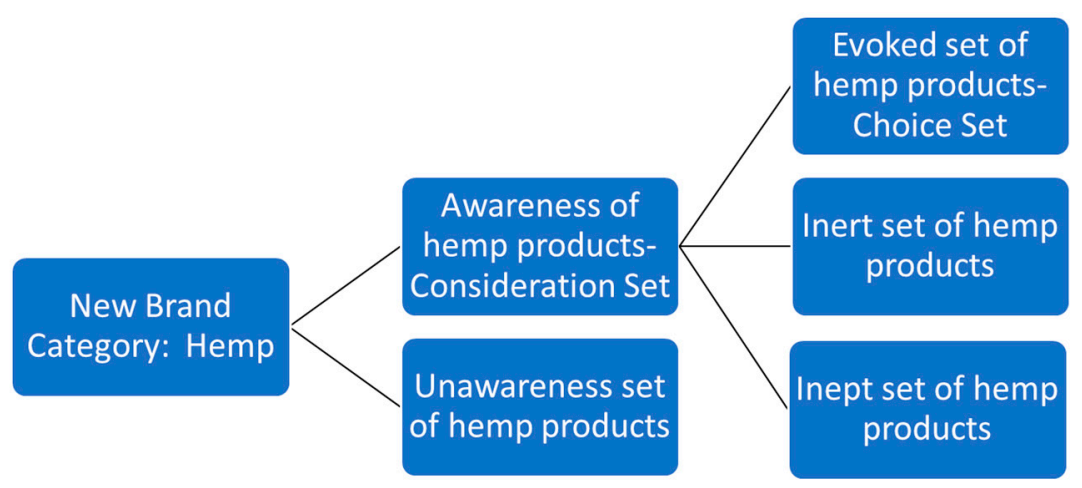

Figure 1. Consumer Consideration Sets for Hemp Based Products (Adapted from Naryana and Markin [61]).

In order to ultimately be in a consumer's evoked/choice set, they must first be aware of hemp products in order to consider them as a choice alternative. Once aware, these products may enter a consumer's evoked set and be chosen for purchase. If a consumer does not have enough information or has not decided whether they will consider purchasing a hemp product, these products become part of the inert set. If a consumer decides not to purchase hemp products, they become part of the 
inept set. If in an inert set, a marketer can provide more information to move hemp products into the evoked set. A marketer can also move these products from the inept set, this would likely be more difficult because a consumer has decided not to consider these products. Given that hemp products are a new category of sustainable products, misconceptions or misinformation may make movement from both inert and inept sets into evoked sets possible.

\section{Materials and Methods}

\subsection{Materials}

This study used data from a statistically representative telephone survey of Vermont residents conducted by the University of Vermont's Center for Rural Studies. The survey was approved by the Institutional Review Board at the University of Vermont and conducted in February and March of 2019. Surveys were executed using computer-aided telephone interviewing (CATI) with trained interviewers. Random sampling was used to choose respondents from a list of landline and cellphone numbers in Vermont. Respondents were called a maximum of three times; any respondents who were not currently residing in Vermont or under the age of 18 were screened out. Response data were secured electronically on a password-protected server at the University of Vermont. Responses with complete information required for the binary logistic regressions ranged from 483 to 514 . The results had a margin of error ranging of $\pm 4.457 \%$ to $\pm 4.321 \%$ with a confidence interval of $95 \%$. IBM ${ }^{\circledR}$ SPSS ${ }^{\circledR}$ Version 26 was used to conduct all statistical analyses.

\subsection{Methods}

This study included demographic characteristics and survey questions related to consumer behavior toward hemp: awareness of the five listed hemp product categories; use of hemp-based products; and support for industrial hemp production in Vermont (Table 1). Awareness of hemp products was based on respondent indication of having heard of the following hemp product categories: hemp CBD oil; hemp clothing or shoes; hemp rope, animal bedding or garden fabric (The rope, animal bedding or garden fabric category will be referred to as "rope" for the remainder of the paper.); hemp paper; and hemp concrete or plastic. Respondents were coded as being generally familiar with hemp if they indicated being familiar with any of the given hemp product categories. Respondents were asked whether they used hemp products and, if they answered yes, were asked to identify those products. Open-ended responses were recoded into the following categories: CBD products; clothes or fabric; personal care products; building materials or tools; food; hemp seed oil (not classified); and other (not classified). Products were put into the CBD category if respondents mentioned CBD explicitly, regardless of the product type (i.e., oils, tincture, edibles, etc.). Products including shampoo, lotion, and salves that did not explicitly mention CBD were placed in the personal care products category. Products in the materials and tools category included rope and string. The hemp seed oil (not classified) category encompassed any oil product that was not explicitly associated with CBD. All other products that did not fit any of the prior hemp categories were placed on the "other" category. Some respondents identified using hemp products but did not provide a comment for what products they use. Thus, the sample of hemp use by category was nine respondents fewer than general hemp use $(n=216$ versus $n=225)$. Support was measured using a 5 - point Likert scale, with 5 being strongly supportive and 1 being strongly opposed to hemp production in Vermont. Responses were recategorized into oppose $(=-1)$, neither supports nor opposes $(=0)$ and supports $(=1)$, where "don't know" responses were recoded as neither supports nor opposes.

Because hemp's production was federally illegal until 2018 and was largely absent from the US marketplace, we assumed that respondents began in the unaware set. If respondents were not familiar with and did not use hemp products, they were categorized as unaware. Respondents can also occupy the general evoked set, where respondents are familiar with product options and, therefore, represent feasible options for potential purchase. If they are not in the evoked set, they are in the inert set, 
which classifies consumers who know about the product but do not have enough information to make a decision or the inept set, which classifies consumers who have no intention of purchasing a hemp product. Our survey does not allow us to distinguish between these two subsets.

Table 1. Survey questions included in the study.

\begin{tabular}{ll}
\hline \multicolumn{1}{c}{ Survey Question } & \multicolumn{1}{c}{ Answer Options } \\
\hline \multirow{2}{*}{$\begin{array}{ll}\text { Please tell me if you've heard of any of the } \\
\text { following hemp products }\end{array}$} & $\begin{array}{l}\text { Hemp CBD }{ }^{1} \text { oil } \\
\text { Hemp animal bedding, rope or garden } \\
\text { fabric }\end{array}$ \\
& $\begin{array}{l}\text { Hemp clothing or shoes } \\
\text { Hemp paper }\end{array}$ \\
\hline \multirow{2}{*}{ Which hemp products do you use? } & $\begin{array}{l}\text { Doesn't use any hemp products } \\
\text { Uses hemp products }\end{array}$ \\
\hline \multirow{2}{*}{$\begin{array}{l}\text { Do you support industrial hemp as an } \\
\text { agricultural product in Vermont? }\end{array}$} & $\begin{array}{l}1=\text { Supports } \\
\text { CBD }\end{array}$ \\
\hline is defined as a naturally occurring, non-psychoactive compound found in hemp plants [25]. \\
\end{tabular}

Information about 6 socio-demographic variables were collected: age, education level, gender, annual income, location, and political affiliation (Table 2). Age was recoded into four categories to mimic the distribution provided by the American Community Survey: 18 to 34, 35 to 49, 50 to 74, and 75 or older. Education was recoded as either less than a Bachelor's degree or a Bachelor's degree or greater, mimicking the approximate median level of education for Vermont [62]. Income was recoded as either less than $\$ 50,000$ per year or greater than $\$ 50,000$ per year, as this is roughly Vermont's median income [62]. Respondents were categorized as residing within Chittenden County, the state's most populous county or as not residing within Chittenden County [63]. Respondents could identify with one of five political affiliations: Republican, Democrat, Independent, Progressive, or not politically affiliated. "Don't know" and refused responses were recoded as missing for all variables included in the study.

Table 2. Descriptive statistics for the independent variables included in the study.

\begin{tabular}{cccc}
\hline Variable & Definition & Percentage/Mean & $\boldsymbol{n}$ \\
\hline \multirow{2}{*}{ Age } & $18-34$ & 10.6 & \\
& $35-49$ & 14.6 & 639 \\
& $50-74$ & 58.2 & \\
\hline Education & $75+$ & 16.6 & 646 \\
\hline Gender & BA degree or greater & 52.0 & 650 \\
\hline Income & Female & 63.2 & 553 \\
\hline Location & Greater than \$50,000 & 66.4 & 680 \\
\hline \multirow{3}{*}{ Political Affiliation } & Chittenden County & 27.2 & \\
& Republican & 15.5 & 611 \\
& Democrat & 30.0 & \\
& Independent & 29.6 & \\
& Progressive & 7.7 & \\
\hline
\end{tabular}

Univariate analyses were first conducted to describe awareness of hemp-based products, use of hemp-based products, and current support for hemp. We used the theory of choice alternatives to provide a snapshot of consumer behavior towards hemp products in Vermont. Bivariate analyses were used to examine each set of choice alternatives under general awareness and choice of hemp products (meaning that respondents were familiar with and use at least one hemp product) and determine whether they are associated with support for hemp production and each socio-demographic variable. We then ran binary logistic regressions for each set, controlling for support and socio-demographic 
variables. We then used bivariate and regression analyses for choice alternative sets specifically for hemp CBD products, the product category most mentioned by respondents

The age of respondents followed a normal distribution with that of the Vermont population [62]. Those with a bachelor's degree or greater were more frequently represented in this survey than census estimates for the state by $15.2 \%$ [62]. The sample of female respondents was higher than the 2018 census estimates for the state by $12.6 \%$, and the sample of those with incomes greater than $\$ 50,000$ per year was greater than census estimates by $9.5 \%$ [62]. The distribution of respondents residing in Chittenden County (27.2\%) was representative of 2018 estimates (26.2\%) [63].

\section{Results}

The majority of respondents are supportive of hemp production in Vermont (75.9\%) and 19.6\% of respondents neither support nor oppose hemp production (Table 3). The majority of respondents are aware of at least one of the listed hemp product categories $(87.4 \%, n=680)$. Respondents are most familiar with hemp CBD oil, hemp clothing or shoes and hemp rope $(78.5 \%, 70.4 \%$, and $58.7 \%$, respectively, $n=680)$. Approximately one-third of respondents use hemp products $(36.8 \%, n=612)$. Respondents most commonly use hemp CBD products; hemp clothing or fabric; hemp personal care products; and hemp materials or tools $(16.7 \%, 10.8 \%, 6.5 \%$, and $6.1 \%$, respectively, $n=603)$. Given that respondents could use more than one hemp product, Figure 2 shows total instances of hemp use by product category. Hemp CBD products and hemp clothing or fabric were the most frequently used products ( $34 \%$ and $22 \%$, respectively).

Table 3. Descriptive statistics for awareness of hemp products, use of hemp products, and support for hemp production in Vermont.

\begin{tabular}{|c|c|c|c|}
\hline Variable & Definition & Percentage & $n$ \\
\hline \multirow{6}{*}{ Hemp Awareness } & General awareness & 87.4 & \multirow{6}{*}{680} \\
\hline & Hemp CBD oil & 78.5 & \\
\hline & Hemp concrete or plastic & 16.2 & \\
\hline & Hemp animal bedding, rope or garden fabric & 58.7 & \\
\hline & Hemp clothing or shoes & 70.4 & \\
\hline & Hemp paper & 35.0 & \\
\hline \multirow{8}{*}{ Hemp Use } & General use & 36.8 & 612 \\
\hline & Hemp CBD products & 16.7 & \multirow{7}{*}{603} \\
\hline & Hemp clothing, shoes or fabric & 10.8 & \\
\hline & Hemp personal care products & 6.5 & \\
\hline & Hemp materials or tools & 6.1 & \\
\hline & Hemp food products & 3.2 & \\
\hline & Hemp oil ${ }^{1}$ & 2.5 & \\
\hline & Other $^{1}$ & 3.3 & \\
\hline \multirow{3}{*}{ Hemp Support } & Supports & 75.9 & \multirow{3}{*}{644} \\
\hline & Neither supports nor opposes & 19.6 & \\
\hline & Opposes & 4.5 & \\
\hline
\end{tabular}

${ }^{1}$ Not classified.

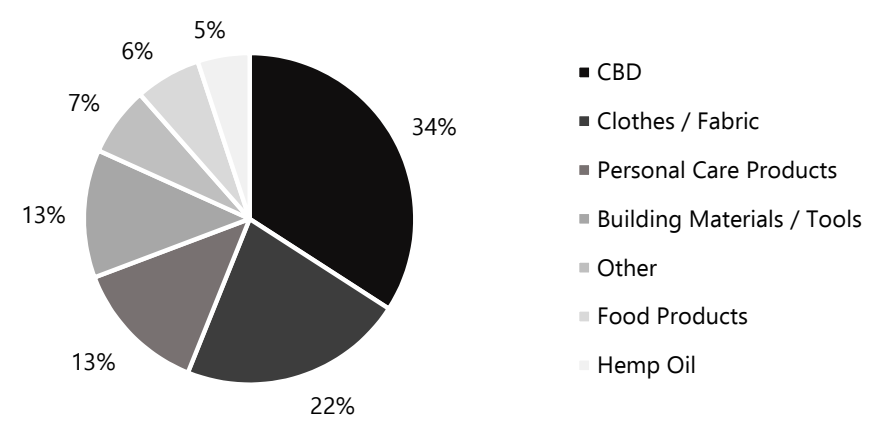

Figure 2. Percentage of total instances of hemp use by product category $(n=296)$. 
After being sorted based on general awareness and use of hemp products, $6.5 \%, 56.7 \%$, and $36.8 \%$ of respondents were put in the choice sets outlined in the conceptual model (see Figure 3$)(n=612)$.

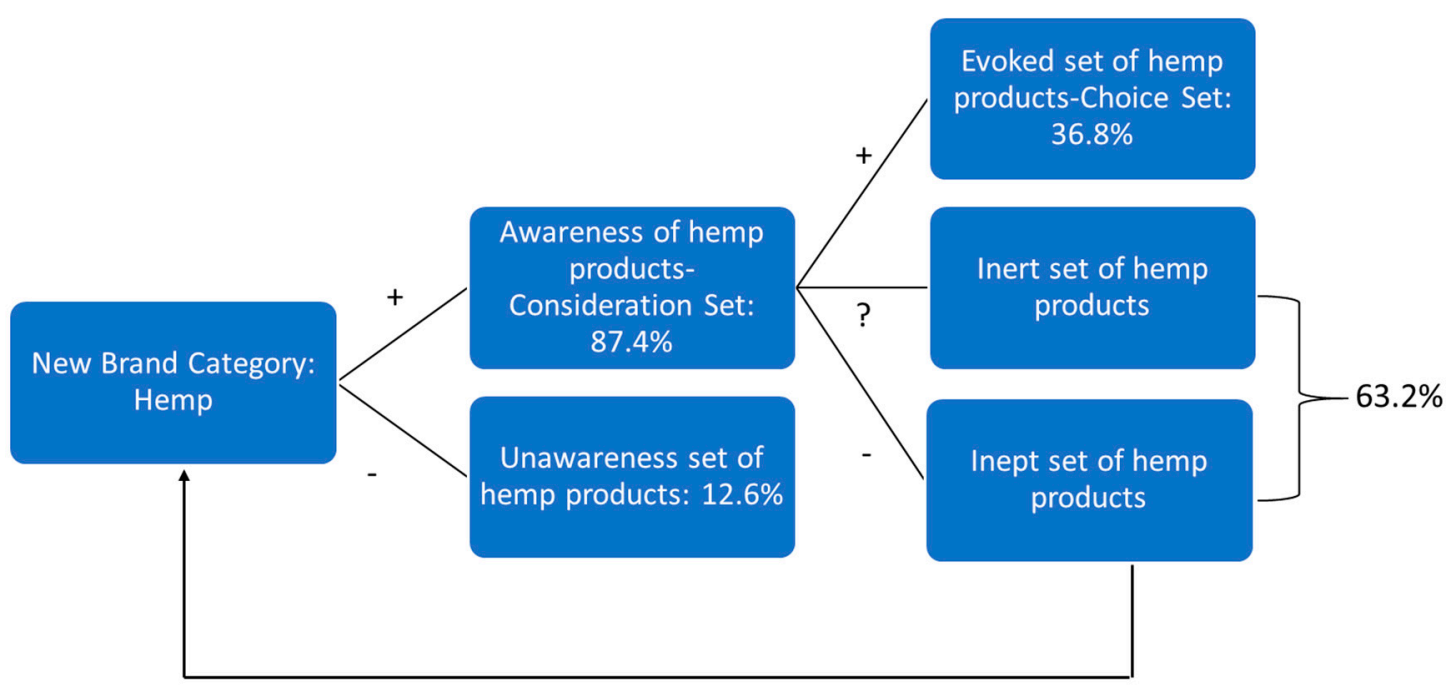

Figure 3. Results of choice categorization for hemp products.

Results of bivariate analyses in Table 4 reveal that age, education, income, and hemp support are significantly associated with those placed in the unaware set. Only hemp support is significantly associated with the consideration set, while age, political affiliation and hemp support are significantly associated with the choice set. Binary regressions for each set reveal fewer significantly associated variables. Respondents 75 years or older were 12.72 times more likely to be in the unaware set compared with the youngest age category $(p=0.021)$ (Table 5$)$. Those supportive of hemp production were less likely to be in the aware set than those opposed by 0.129 percentage points $(p=0.003)$. None of the socio-demographic variables, as well as support for hemp production, were significantly associated with respondents in the consideration set. After removal of hemp support due to the serial collinearity, regression results reveal that Progressive respondents were 2.74 times more likely to be in the choice set than Republican respondents $(p=0.014)$.

When sorted by awareness and use of hemp CBD products, $15.9 \%, 67.3 \%$, and $16.7 \%$ of respondents were sorted into the unaware, consideration and choice sets, respectively, $(n=603)$. Table 6 shows the results of the bivariate analyses. Age, education and hemp support are significantly associated with those unaware of hemp CBD products. Age is significantly associated with the consideration set. Political affiliation and hemp support are significantly associated with the choice set. Binary regressions reveal that respondents 75 years or older were 11.335 times more likely to be in the unaware set for hemp CBD products compared to the youngest age category ( $p<0.001$ ) (Table 7$)$. Respondents 75 years and older were also less likely to be in the consideration set by 0.214 percentage points $(p=0.001)$. Respondents with a bachelor's degree or greater were 1.665 times more likely to be in the consideration set for hemp CBD products $(p=0.023)$ than those with less than a bachelor's degree. Hemp support was removed from the regression for the choice set due to the serial collinearity. The results reveal that Independent respondents were 2.453 times more likely to be in the choice set for hemp CBD products than Republican respondents $(p=0.025)$. 
Table 4. Bivariate results for the unaware, consideration, and choice sets for general hemp awareness and use.

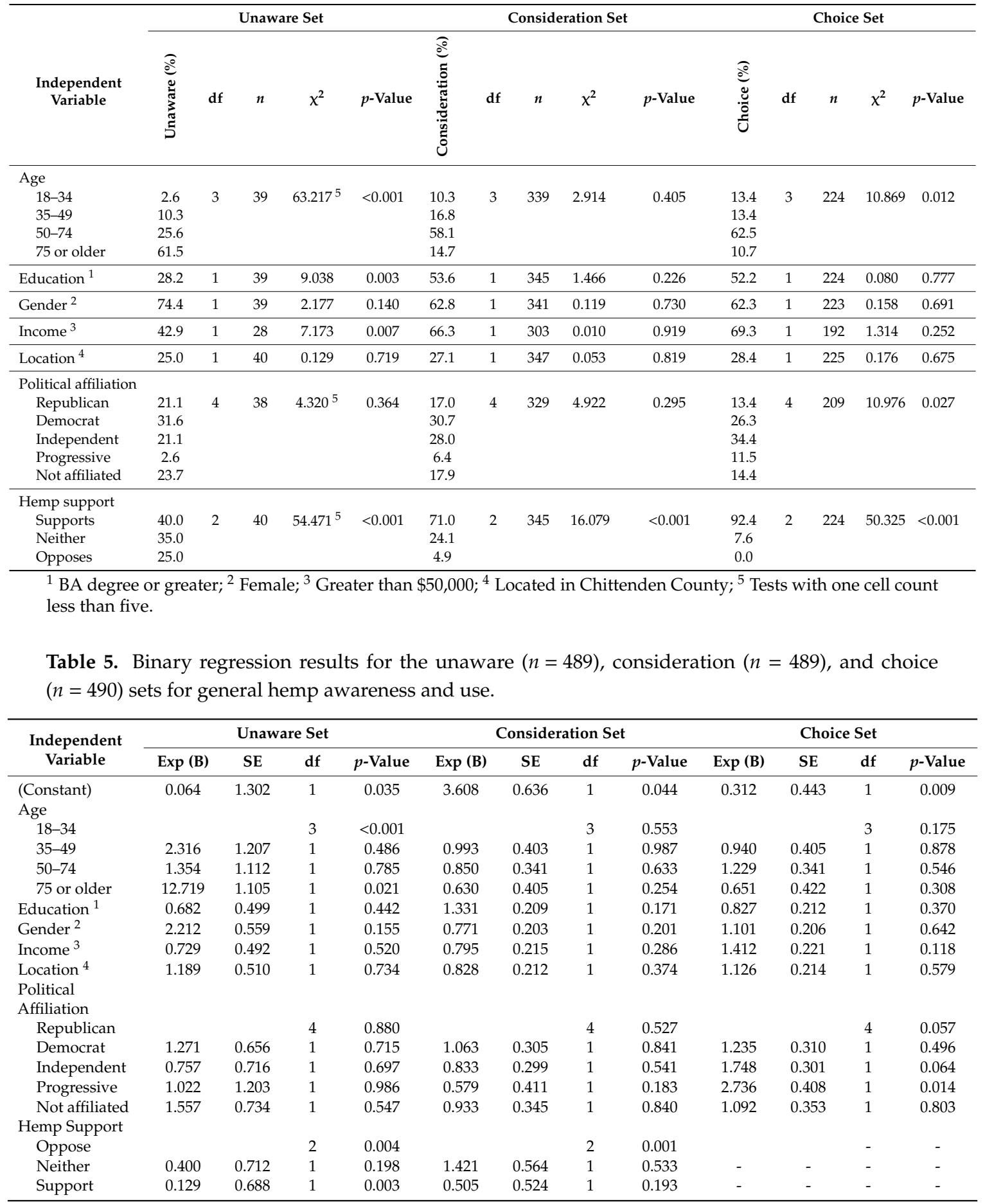

${ }^{1}$ BA degree or greater; ${ }^{2}$ Female; ${ }^{3}$ Greater than $\$ 50,000 ;{ }^{4}$ Located in Chittenden County. 
Table 6. Bivariate results for the unaware, consideration and choice sets for awareness and use of hemp CBD products.

\begin{tabular}{|c|c|c|c|c|c|c|c|c|c|c|c|c|c|c|c|}
\hline \multirow[b]{2}{*}{$\begin{array}{l}\text { Independent } \\
\text { Variable }\end{array}$} & \multicolumn{5}{|c|}{ Unaware Set } & \multicolumn{5}{|c|}{ Consideration Set } & \multicolumn{5}{|c|}{ Choice Set } \\
\hline & 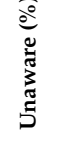 & df & $n$ & $x^{2}$ & $p$-Value & 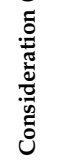 & df & $n$ & $x^{2}$ & $p$-Value & 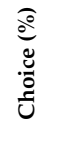 & df & $n$ & $x^{2}$ & $p$-Value \\
\hline $35-49$ & 12.9 & & & & & 16.0 & & & & & 14.0 & & & & \\
\hline $50-74$ & 38.7 & & & & & 59.8 & & & & & 68.0 & & & & \\
\hline 75 or older & 44.1 & & & & & 11.3 & & & & & 10.0 & & & & \\
\hline Education $^{1}$ & 41.1 & 1 & 95 & 5.016 & 0.025 & 53.7 & 1 & 404 & 2.248 & 0.134 & 53.0 & 1 & 100 & 0.096 & 0.757 \\
\hline Gender $^{2}$ & 68.4 & 1 & 95 & 1.445 & 0.229 & 61.3 & 1 & 400 & 1.541 & 0.214 & 64.6 & 1 & 99 & 0.144 & 0.704 \\
\hline Republican & 22.2 & 4 & 90 & 7.754 & 0.101 & 15.2 & 4 & 382 & 5.907 & 0.206 & 11.6 & 4 & 95 & 12.452 & 0.014 \\
\hline Democrat & 30.0 & & & & & 29.3 & & & & & 27.4 & & & & \\
\hline Independent & 27.8 & & & & & 27.7 & & & & & 42.1 & & & & \\
\hline Progressive & 2.2 & & & & & 8.9 & & & & & 10.5 & & & & \\
\hline Not affiliated & 17.8 & & & & & 18.8 & & & & & 8.4 & & & & \\
\hline \multicolumn{16}{|l|}{ Hemp support } \\
\hline Supports & 53.1 & 2 & 96 & $37.246^{5}$ & $<0.001$ & 77.9 & 2 & 403 & 1.352 & 0.509 & 94.1 & 2 & 95 & $20.975^{5}$ & $<0.001$ \\
\hline Neither & 35.4 & & & & & 18.1 & & & & & 5.9 & & & & \\
\hline Opposes & 11.5 & & & & & 4.0 & & & & & 0.0 & & & & \\
\hline
\end{tabular}

Table 7. Binary regression results for the unaware, consideration, and choice sets for awareness and use of hemp CBD products.

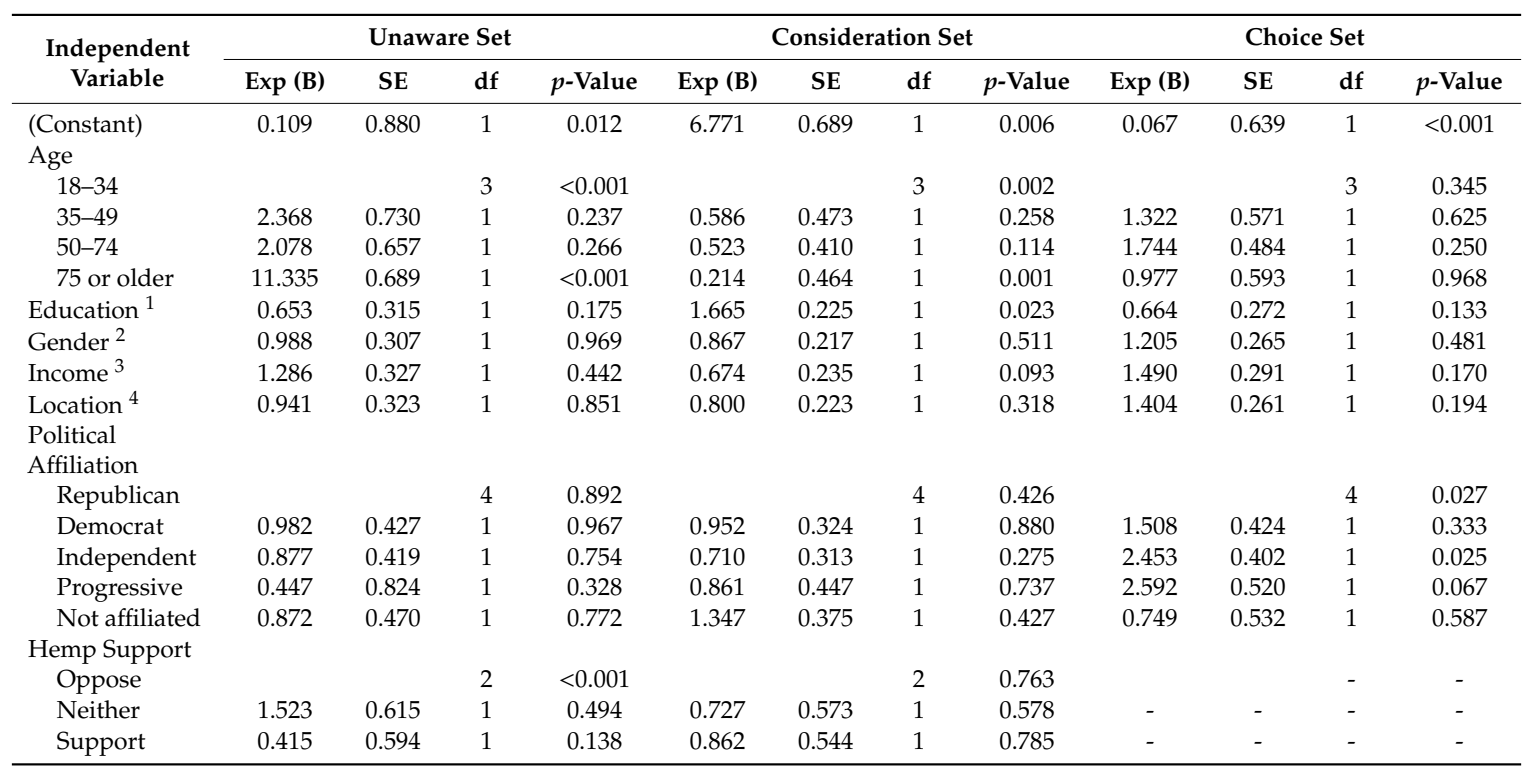

${ }^{1}$ BA degree or greater; ${ }^{2}$ Female; ${ }^{3}$ Greater than $\$ 50,000 ;{ }^{4}$ Located in Chittenden County.

\section{Discussion}

Survey results revealed high rates of support for hemp production in Vermont, as well as awareness of at least one type of hemp product. Consumers' evoked choice set of hemp-based products was lower, with about one-third of respondents identified as using hemp products. Given the nascency of the market, this result offers a hopeful outlook for the consumption of sustainable hemp products, with room to grow in the future as growers shift cultivation strategies from research to 
commercialization and processors gain capacity to match that which hemp growers can provide and consumers desire $[64,65]$. A lower use rate may also reflect the inability of hemp to be priced competitively with cheaper alternatives such as cotton and may reinforce predictions of hemp's role in small-scale, niche markets $[7,19,27]$.

Evoked/choice sets for hemp products overall, and CBD specifically, are associated with political affiliation, where Democrat and Progressive respondents are more likely to choose hemp products. Given hemp's historical ties to marijuana and classification as a controlled substance since 1970, these results may be indicative of continued political stigma towards hemp [26]. Recent discussions about hemp in the academic and business communities have asserted that if the hemp sector is to grow, marketers must find ways to highlight the sustainable and quality characteristics of hemp and depoliticize the marketplace [66]. Our findings support this idea. Findings indicate a need for further public education on hemp cultivation and products, as well as future research on methods to more effectively differentiate hemp from marijuana.

Many local reports on hemp development in Vermont, as well as industry data on hemp consumption in the US, identify CBD as a primary motivator behind rising interest in hemp production $[30,52,53,67,68]$. Findings in this survey do find that CBD is a prominent player in the current marketplace, with hemp CBD being most aware of and chosen by respondents (Figure 2). However, other categories of hemp-based products are of interest to consumers. Respondents are also familiar with and use hemp clothing, hemp personal care products, and hemp rope. Total instances of hemp product use in this study reveal clothing and textiles as playing a more prominent role compared to industry findings (Figure 2) [30]. These findings challenge the idea that CBD is the single driving force behind consumer demand for hemp in Vermont and may indicate opportunity for producers to pursue other sustainable, value-added hemp products such as hemp fiber.

Initially it appears that, overall, there is support for and interest in hemp and the variety of sustainable products hemp can produce. This study provides a baseline from which to examine efforts to study why consumers move from a consideration to an evoked/choice set and offers the first evidence-based data on consumer demand for hemp since its resurgence after nearly 80 years of regulatory obstacles. These findings offer valuable insight for producers currently navigating this new market and may signal opportunity for a wider market of sustainable hemp products than is currently available. Future research should expand upon these findings and examine the motivations, attitudes and values behind consumer use of hemp-based products in order to further assist producers and marketers of this new crop and develop comprehensive segmentation of the sustainable hemp consumer, including the motivations consumers have when moving from a consideration set to an evoked/choice, inept or inert segmentation set.

\section{Conclusions}

Recent changes to federal regulations have expanded market potential for hemp products. The longevity and viability of hemp production in Vermont, and the nation, will be influenced by the availability of market research, which is currently limited [30]. Thus, this study provides insight to consumer segments for hemp products in order to help inform hemp policymakers and producers seeking to effectively participate in this renewed agricultural sector and market hemp's sustainability as a crop and product. Results offer a positive outlook, with the majority of respondents supportive of hemp production in Vermont and aware of hemp-based products. Hemp awareness by category also reveals consumers as most familiar with hemp CBD oil, which appears in line with current perceptions of hemp growth in Vermont. This study also suggests that other hemp-based products, including clothing, fabric and rope, signal an opportunity for Vermont to diversify its market to be more inclusive of the many sustainable products hemp can offer. Additional room for growth is evident, as the frequency of hemp use is approximately half that of awareness and support. This study suggests that socio-demographic variables have inconsistent associations with consumer demand for hemp, as they do with other sustainable products reviewed in the literature review section of this article. Given 
hemp's complex regulatory past and dynamic product potential, the next iteration of data collection will incorporate the complex decision processes consumers undertake when making decisions about hemp products. Attitudes regarding hemp, its associated products, and its implications to Vermont will be evaluated which is a limitation of this study [2].

This study finds that people with more progressive political affiliations are more likely to be placed into the choice set for hemp-based products. Additional research on underlying reasons behind this segmentation could help inform how to move politically conservative consumers into the hemp evoked set. Jung and Mittal [69] offer some insight into this area, characterizing more conservative consumers as seeking "predictability and control in their environment" through compliance to authority, social control, conventionalism, and security. Hemp products, to conservative respondents, may invoke the idea that hemp is equivalent to illegal drugs or is an unconventional, uncertain choice. This is an area fruitful for more research.

For those consumers classified into the inert and inept sets, further research is needed to identify whether they do not have enough information to make a decision or have tried hemp products and found them to not meet their expectations or standards of quality. Regardless, more research is needed to identify which characteristics of hemp are the most appealing to consumers and to ensure that products meet and exceed minimum quality standards. This is a pertinent issue for products containing cannabidiol, in terms of inconsistency of levels in products, exacerbated by a lack of regulation clarity at both the State and Federal level, which may be reflected at the end of the hemp value chain: the consumer [70].

Author Contributions: J.K.: project lead, including conceptualization, instrument design, methodology, supervision, drafting, reviewing and editing; H.L.: data curation, writing original draft, and reviewing and editing; K.G.: conceptualization and data curation. All authors have read and agreed to the published version of the manuscript.

Funding: This research received no external funding.

Acknowledgments: Thank you to the UVM Center for Rural Studies for data collection, as well as the UVM Department of Community Development and Applied Economics for administrative and technical support.

Conflicts of Interest: The authors declare no conflict of interest.

\section{References}

1. De Medeiros, J.F.; Ribeiro, J.L.D.; Cortimiglia, M.N. Success factors for environmentally sustainable product innovation: A systematic literature review. J. Clean. Prod. 2014, 65, 76-86. [CrossRef]

2. Verain, M.C.D.; Bartels, J.; Dagevos, H.; Sijtsema, S.J.; Onwezen, M.C.; Antonides, G. Segments of sustainable food consumers: A literature review: Segments of sustainable food consumers. Int. J. Consum. Stud. 2012, 36, 123-132. [CrossRef]

3. Gilg, A.; Barr, S.; Ford, N. Green consumption or sustainable lifestyles? Identifying the sustainable consumer. Futures 2005, 37, 481-504. [CrossRef]

4. Borkowska, B.; Bialkowska, P. Evaluation of consumer awareness of hemp and its applications in different industries. Sci. J. Gdyn. Marit. Univ. 2019, 110, 7-16. [CrossRef]

5. Finnan, J.; Styles, D. Hemp: A more sustainable annual energy crop for climate and energy policy. Energy Policy 2013, 58, 152-162. [CrossRef]

6. Das, L.; Liu, E.; Saeed, A.; Williams, D.W.; Hu, H.; Li, C.; Ray, A.E.; Shi, J. Industrial hemp as a potential bioenergy crop in comparison with kenaf, switchgrass and biomass sorghum. Bioresour. Technol. 2017, 244, 641-649. [CrossRef] [PubMed]

7. Johnson, R. Hemp as an Agricultural Commodity; Congressional Research Service: Washington, DC, USA, 2018.

8. Maalouf, C.; Ingrao, C.; Scrucca, F.; Moussa, T.; Bourdot, A.; Tricase, C.; Presciutti, A.; Asdrubali, F. An energy and carbon footprint assessment upon the usage of hemp-lime concrete and recycled-PET façades for office facilities in France and Italy. J. Clean. Prod. 2018, 170, 1640-1653. [CrossRef]

9. Meijer, W.J.; van der Werf, H.M.; Mathijssen, E.W.; van den Brink, P.W. Constraints to dry matter production in fibre hemp (Cannabis sativa L.). Eur. J. Agron. 1995, 4, 109-117. [CrossRef] 
10. Thompson, E.C.; Berger, M.C.; Allen, S.N. Economic Impact of Industrial Hemp in Kentucky; University of Kentucky, Center for Business and Economic Research: Lexington, KY, USA, 1998.

11. Devinsky, O.; Cilio, M.R.; Cross, H.; Fernandez-Ruiz, J.; French, J.; Hill, C.; Katz, R.; Di Marzo, V.; Jutras-Aswad, D.; Notcutt, W.G.; et al. Epilepsy and other neuropsychiatric disorders. Epilepsia 2014, 55, 791-802. [CrossRef]

12. Rosenberg, E.C.; Tsien, R.W.; Whalley, B.J.; Devinsky, O. Cannabinoids and epilepsy. Neurotherapeutics 2015, 12, 747-768. [CrossRef]

13. Zhornitsky, S.; Potvin, S. Cannabidiol in humans-The quest for therapeutic targets. Pharmaceuticals 2012, 5, 529-552. [CrossRef] [PubMed]

14. Miriţoiu, C.M.; Burada, C.O.; Stănescu, M.M.; Bolcu, D.; Pădeanu, A.; Bolcu, A. Comparisons between some composite materials reinforced with hemp fibers. In Proceedings of the 35th Danubia Adria Symposium on Advances in Experimental Mechanics, Sinaia, Romania, 25-28 September 2018; pp. 499-507.

15. Karus, M.; Vogt, D. European hemp industry: Cultivation, processing and product lines. Euphytica 2004, 140, 7-12. [CrossRef]

16. Montford, S.; Small, E. A comparison of the biodiversity friendliness of crops with special reference to hemp (Cannabis sativa L.). J. Int. Hemp Assoc. 1999, 6, 53-63.

17. Montford, S.; Small, E. Measuring harm and benefit: The biodiversity friendliness of Cannabis sativa. Glob. Biodivers. 1999, 8, 3-13.

18. Bouloc, P.; van der Werf, H.M.G. The role of hemp in sustainable development. In Hemp: Industrial Production and Uses; Bouloc, P., Allegret, S., Arnaud, L., Eds.; CABI: Wallingford, CT, USA, 2013; pp. 278-289. ISBN 978-1-84593-793-5.

19. Fortenbery, T.R.; Bennett, M. Opportunities for commercial hemp production. Rev. Agric. Econ. 2004, 26, 97-117. [CrossRef]

20. Kraenzel, D.; Petry, T.; Nelson, B.; Anderson, M.; Mathern, D.; Todd, R. Industrial Hemp as an Alternative Crop in North Dakota; The Institute for Natural Resources and Economic Development, North Dakota State University: Fargo, ND, USA, 1998; pp. 1-23.

21. Kolosov, C.A. Evaluating the public interest: Regulations of industrial hemp under the Controlled Substances Act. UCLA Law Rev. 2009, 237-274.

22. Small, E. Evolution and classification of Cannabis sativa (marijuana, hemp) in relation to human utilization. Bot. Rev. 2015, 81, 189-294. [CrossRef]

23. Rodale Institute Industrial Hemp Trial. Available online: https://rodaleinstitute.org/science/industrial-hemptrial/ (accessed on 2 January 2020).

24. Ebskamp, M.J.M. Engineering flax and hemp for an alternative to cotton. Trends Biotechnol. 2002, 20, 229-230. [CrossRef]

25. World Health Organization. Cannabidiol (CBD): Critical Review Report; Expert Committee on Drug Dependence: Geneva, Switzerland, 2018.

26. Malone, T.; Gomez, K. Hemp in the United States: A case study of regulatory path dependence. Appl. Econ. Perspect. Policy 2019, 41, 199-214. [CrossRef]

27. Cherney, J.H.; Small, E. Industrial hemp in North America: Production, politics and potential. Agronomy 2016, 6, 58. [CrossRef]

28. Agriculture Improvement Act of 2018; United States Congress: Washington, DC, USA, 2018.

29. Mark, T.; Shepherd, J.; Olson, D.; Snell, W.; Proper, S.; Thornsbury, S. Economic Viability of Industrial Hemp in the United States: A Review of State Pilot Programs; United States Department of Agriculture: Washington, DC, USA, 2020; p. 83.

30. Stansbury, L. 2017 Annual Retail Sales for Hemp Products Estimated at $\$ 820$ Million. Available online: https://www.votehemp.com/press_releases/2017-annual-retail-sales-for-hemp-products/ (accessed on 2 January 2020).

31. Ellison, S. National Hemp Research Needs Survey Results 2020. In Proceedings of the National Hemp Research \& Education Virtual Conference, held remotely, 1 July-5 August 2020.

32. Verbeke, W. Consumer acceptance of functional foods: Socio-demographic, cognitive and attitudinal determinants. Food Qual. Prefer. 2005, 16, 45-57. [CrossRef]

33. Tan, L.P.; Johnstone, M.-L.; Yang, L. Barriers to green consumption behaviours: The roles of consumers' green perceptions. Australas. Mark. J. AMJ 2016, 24, 288-299. [CrossRef] 
34. Panzone, L.; Hilton, D.; Sale, L.; Cohen, D. Socio-demographics, implicit attitudes, explicit attitudes, and sustainable consumption in supermarket shopping. J. Econ. Psychol. 2016, 55, 77-95. [CrossRef]

35. Bhaskaran, S.; Hardley, F. Buyer beliefs, attitudes and behaviour: Foods with therapeutic claims. J. Consum. Mark. 2002, 19, 591-606. [CrossRef]

36. Ha-Brookshire, J.E.; Norum, P.S. Willingness to pay for socially responsible products: Case of cotton apparel. J. Consum. Mark. 2011, 28, 344-353. [CrossRef]

37. Hustvedt, G.; Bernard, J.C. Consumer willingness to pay for sustainable apparel: The influence of labelling for fibre origin and production methods. Int. J. Consum. Stud. 2008, 32, 491-498. [CrossRef]

38. Choi, S.; Ng, A.; Park, S.-J. Purchase Decision: Sustainability of Mountain Pine Beetle Wood Concrete Products. For. Prod. J. 2011, 61, 333-339. [CrossRef]

39. Stranieri, S.; Ricci, E.C.; Banterle, A. Convenience food with environmentally-sustainable attributes: A consumer perspective. Appetite 2017, 116, 11-20. [CrossRef] [PubMed]

40. Egan, B.; Hodgkins, C.; Shepherd, R.; Timotijevic, L.; Raats, M. An overview of consumer attitudes and beliefs about plant food supplements. Food Funct. 2011, 2, 747. [CrossRef] [PubMed]

41. Sirois, F.M.; Purc-Stephenson, R.J. Consumer Decision Factors for Initial and Long-Term Use of Complementary and Alternative Medicine. Complement. Health Pract. Rev. 2008, 13, 3-19. [CrossRef]

42. An Act Relating to Modifying the Requirements for Hemp Production in the State of Vermont; Vermont Legislature: Vermont, VT, USA, 2013.

43. Legitimacy of Industrial Hemp Research; U.S. Congress: Washington, DC, USA, 2014.

44. Darby, H.; Gupta, A.; Cummings, E.; Ruhl, L.; Ziegler, S. Industrial Grain Hemp Variety Trial. Northwest Crop. Soils Program 2017, 77, 1-10.

45. Darby, H.; Gupta, A.; Cummings, E.; Ruhl, L.; Ziegler, S. Industrial Cannabidiol Hemp Report. Northwest Crop. Soils Program 2017, 57, 1-6.

46. Darby, H.; Gupta, A.; Cubins, J.; Ruhl, L. Industrial Hemp Seeding Rate Trial. Northwest Crop. Soils Program 2016, 93, 1-7.

47. Darby, H.; Gupta, A.; Cummings, E.; Cubins, J.; Emick, H. Industrial Hemp Weed Control Trial. Northwest Crop. Soils Program 2016, 92, 19.

48. Hallenback, T. Vermont Hemp Farmers Find Fertile Ground in CBD Crop. Seven Days, 13 September 2017.

49. Kalish, J. Vermont's Third Hemp-Growing Season: More Acreage, New Products. Vermont Public Radio News, 16 May 2016.

50. Singh, L. Vermont Looks To Booming Hemp Business. National Public Radio, 19 August 2018.

51. Nichols, K. Hemp Report: Top 10 U.S. States; Hemp Industry Daily: Lakewood, CO, USA, 2018.

52. Lindholm, J.; Smith, M.F. “Like A Gold Rush!” Vermont's Booming Summer Hemp Crop. Vermont Public Radio News, 2 August 2019.

53. Weiss-Tisman, H. Vermont Hemp Growers, Processors Look Back On A Season Of Lessons Learned. Vermont Public Radio News, 3 November 2019.

54. Vermont Agency of Agriculture, Food and Markets Hemp Resources and Guidance. Available online: https://agriculture.vermont.gov/public-health-agricultural-resource-management-division/hempprogram/hemp-resources-and-guidance (accessed on 2 January 2020).

55. Kalish, J. CBD Products A Prominent Piece Of Vermont's Expanding Hemp Industry. Vermont Public Radio News, 9 October 2018.

56. Ledbetter, S. Eager to cash in on CBD craze, hundreds of Vermont farmers are now harvesting hemp. National Public Radio, 26 September 2019.

57. McCallum, K. Sow Much Hemp: A Large Harvest Prompts Fears of Oversupply. Seven Days, 30 October 2019.

58. Wallace Allen, A. Making it in Vermont: Hemp producers ready to grow. VTDigger, 20 January 2019.

59. Marihuana Tax Act of 1937; U.S. Congress: Washington, DC, USA, 1937.

60. Narayana, C.L.; Markin, R.J. Consumer behavior and product performance: An alternative conceptualization. J. Mark. 1975, 39, 1-6. [CrossRef]

61. Howard, J.A.; Sheth, J.N. The Theory of Buyer Behavior; John Wiley and Sons: New York, NY, USA, 1969.

62. United States Census Bureau QuickFacts: Vermont. Available online: https://www.census.gov/quickfacts/VT (accessed on 1 July 2020).

63. Brozicevic, P.; Nyland-Funke, M. 2018 Vermont Population Estimates by County, Town and Age; Vermont Department of Health: Burlington, VT, USA, 2019. 
64. Chen, P. Lack of hemp processing capacity hurts sales for growers. VTDigger, 6 August 2019.

65. Healy, C. Vermont Hemp Harvest Brings In Less Green Than Farmers Hoped For. New England Public Radio, 22 October 2019.

66. Shea, K. Charlotte's Web Perspectives of the Hemp Market 2020. In Proceedings of the National Hemp Research \& Education Virtual Conference, held remotely, 1 July-5 August 2020.

67. Whitcomb, K. Banking on cannabis: Federal law hampering growth. Rutland Herald, 13 September 2019.

68. Stansbury, L. Annual Retail Sales for Hemp-Derived CBD Products Estimated to Exceed \$646 Million by 2022. Available online: https://www.votehemp.com/press_releases/annual-retail-sales-for-hemp-derivedcbd-products-estimated-exceed-646-million-by-2022/ (accessed on 2 January 2020).

69. Jung, J.; Mittal, V. Political identity and the consumer journey: A research review. J. Retail. 2020, 96, 55-73. [CrossRef]

70. VanDolah, H.J.; Bauer, B.A.; Mauck, K.F. Clinicians' Guide to Cannabidiol and Hemp Oils. Mayo Clin. Proc. 2019, 94, 1840-1851. [CrossRef]

(C) 2020 by the authors. Licensee MDPI, Basel, Switzerland. This article is an open access article distributed under the terms and conditions of the Creative Commons Attribution (CC BY) license (http://creativecommons.org/licenses/by/4.0/). 